\title{
Preoptic-Raphé Connections for Thermoregulatory Vasomotor Control
}

\author{
Mutsumi Tanaka, ${ }^{1}$ Michael J. McKinley, ${ }^{1,2}$ and Robin M. McAllen ${ }^{1,3}$ \\ ${ }^{1}$ Howard Florey Institute, Florey Neuroscience Institutes, and Departments of ${ }^{2}$ Physiology and ${ }^{3}$ Anatomy and Cell Biology, University of Melbourne, \\ Parkville, Victoria 3010, Australia
}

Blood flow to glabrous skin such as the rat's tail determines heat dissipation from the body and is regulated by sympathetic vasoconstrictor nerves. Tail vasoconstrictor activity is tonically inhibited by neurons in two distinct preoptic regions, rostromedial (RMPO) and caudolateral (CLPO) regions, whose actions may be via direct projections to medullary raphé premotor neurons. In urethaneanesthetized rats, we sought single preoptic neurons that were antidromically activated from the medullary raphé and could subserve this function. Nine of 45 raphé-projecting preoptic neurons, predominantly in the CLPO, showed spontaneous activity under warm conditions and were inhibited by cooling the trunk skin (warm-responsive). Unexpectedly, 14 raphé-projecting preoptic neurons (mostly in the RMPO) were activated by skin cooling (cold-responsive), suggesting that an excitatory pathway from this region could contribute to tail vasoconstriction. Supporting this, neuronal disinhibition in the RMPO by microinjecting the $\mathrm{GABA}_{\mathrm{A}}$ receptor antagonist bicuculline ( 0.5 $\mathrm{mM}, 15 \mathrm{nl}$ ) caused a rapid increase in tail sympathetic nerve activity (SNA). Similar injections into the CLPO were without effect. Electrical stimulation of the RMPO also activated tail SNA, with a latency 25 ms longer than to stimulation of the medullary raphé. Injection of the glutamate receptor antagonist kynurenate $(50 \mathrm{mM}, 120 \mathrm{nl})$ into the medullary raphé suppressed tail SNA responses to both RMPO bicuculline and skin cooling. These findings suggest that both inhibitory and excitatory descending drives regulate tail vasoconstriction in the cold and that warm- and cold-responsive raphé-projecting preoptic neurons may mediate these actions.

\section{Introduction}

Body temperature is regulated in part by controlling the circulation to the periphery, to increase or decrease heat dissipation to the environment. The rat's tail is a major organ of heat loss, and its circulation is regulated by sympathetic vasoconstrictor nerves under the control of the brain. Sympathetic premotor neurons controlling the tail circulation are located in the rostral medullary raphé (Smith et al., 1998; Tanaka et al., 2002, 2007; Nakamura et al., 2004; Ootsuka et al., 2004; Ootsuka and Blessing, 2005; Ootsuka and McAllen, 2005) and to a lesser extent the rostral ventrolateral medulla (Tanaka et al., 2002; Ootsuka and McAllen, 2005; Rathner et al., 2008).

The preoptic area is a key structure for body temperature regulation; it receives and integrates temperature information from the skin and core and then sends efferent signals to thermoregulatory effector organs such as tail vessels and interscapular brown adipose tissue (BAT). Under warm conditions, brain transection caudal to the preoptic area (Rathner et al., 2008) or neu-

Received Dec. 9, 2010; revised Feb. 3, 2011; accepted Feb. 7, 2011.

M.T., M.J.M., and R.M.M. designed research; M.T. performed research; M.T., M.J.M., and R.M.M. analyzed data; M.T., M.J.M., and R.M.M. wrote the paper.

This study was supported by National Health and Medical Research Council of Australia (NHMRC) Project Grants 454601 and 628657, the Robert J. Jr. and Helen C. Kleberg Foundation, and the Leila Y. and G. Harold Mathers Trust. R.M.M. and M.J.M. hold NHMRC Fellowships 232305 and 454369. We are most grateful to David Trevaks for his expert help with technical and computing aspects of this study.

Correspondence should be addressed to Dr. Robin M. McAllen, Howard Florey Institute, University of Melbourne, Parkville, VIC 3010, Australia. E-mail: rmca@florey.edu.au.

DOI:10.1523/JNEUROSCI.6433-10.2011

Copyright $\odot 2011$ the authors $\quad 0270-6474 / 11 / 315078-11 \$ 15.00 / 0$ ronal inhibition in the preoptic area (Osborne and Kurosawa, 1994) induce tail vasoconstriction, indicating that the tail vasomotor supply is under tonic inhibitory regulation by preoptic neurons. We recently showed that neurons in two distinct preoptic loci contribute to this tonic inhibition; a rostromedial preoptic region (RMPO) surrounding the organum vasculosum of the lamina terminalis and the median preoptic nucleus ( $\mathrm{MnPO})$, and a preoptic region centered $\sim 1 \mathrm{~mm}$ caudolaterally (CLPO) (Tanaka et al., 2009). In contrast to thermogenic pathways, the tail vasoconstrictor pathway has no obligatory synaptic relay in the dorsomedial hypothalamus (DMH) (Rathner et al., 2008), suggesting that RMPO and CLPO neurons may directly inhibit raphé premotor neurons.

The first aim of the present study was to identify electrophysiologically the RMPO and CLPO neurons that project directly to the medullary raphe and then test whether they respond in the predicted manner to skin or core temperatures. The second aim was to investigate how those raphé-projecting preoptic neurons contribute to the thermoregulatory control of tail vessels.

\section{Materials and Methods}

Sixty-one adult male Sprague Dawley rats $(290-410$ g) were used in this study. All experiments were performed in accordance with guidelines of the National Health and Medical Research Council of Australia and were approved by the Animal Experimentation Ethics Committee of the Howard Florey Institute.

Animals were anesthetized initially with pentobarbital sodium $(60 \mathrm{mg} /$ $\mathrm{kg}$, i.p.), and the hair over the trunk was shaved. The trachea was cannulated, and animals were then artificially ventilated with $2.0 \%$ isoflurane (Forthane; Abbott Australia Pty Ltd.) in pure oxygen. Respiratory pres- 
sure was monitored via a pressure transducer attached to a side tube, and expired $\mathrm{CO}_{2}$ concentration was monitored by $\mathrm{CO}_{2}$ analyzer (ADC). Ventilation was adjusted to keep expired $\mathrm{CO}_{2}$ between 3 and $4.5 \%$. The right femoral artery and vein were cannulated for monitoring blood pressure and intravenous administration of drugs, respectively. A water-perfused SILASTIC jacket was positioned around the animal's shaved trunk, and the temperature of the perfusion water was used to manipulate skin and core temperature (Owens et al., 2002). Skin temperature was measured as the average of three thermocouples placed across the trunk between the skin and water jacket. Core temperature was measured by a thermocouple inserted $5 \mathrm{~cm}$ into the rectum. Core temperature was maintained between $\sim 37$ and $38^{\circ} \mathrm{C}$ during surgery by perfusion of the jacket at $150-$ $180 \mathrm{ml} / \mathrm{min}$ with water from a reservoir maintained at $39-42^{\circ} \mathrm{C}$.

The animal was then mounted prone in a stereotaxic apparatus, and burr holes were made in the skull over the rostral hypothalamus and the medulla. When surgery was complete, isoflurane was gradually withdrawn and replaced by urethane (1.0-1.2 g/ $\mathrm{kg}$, i.v.). The depth of anesthesia was assessed at intervals throughout the experiment by testing withdrawal and corneal reflexes, and small additional doses of urethane (25-50 mg, i.v.) were administered if necessary to abolish those reflexes.

\section{Raphé-projecting preoptic neuron recording}

In 30 rats, single-unit recordings were made extracellularly from the preoptic area while electrical stimuli were delivered to the medullary raphé. To position the stimulating electrode (concentric bipolar; Rhodes Medical Instruments) in the medullary raphé, the caudal pole of the facial nucleus (CP7) was first identified by using the electrode to record the antidromic field potential to electrical stimulation of the facial nerve (Brown and Guyenet, 1985). Once the facial nucleus had been mapped, the electrode was repositioned to the midline $\sim 0.5 \mathrm{~mm}$ rostral to CP7. Before stimulating the medullary raphé, pancuronium bromide (1-1.5 $\mathrm{mg} / \mathrm{kg}$; AstraZeneca) was given intravenously to paralyze the animal. Supplementary doses of pancuronium ( $1 \mathrm{mg} / \mathrm{kg}$, i.v.) were administered to restore paralysis each time after its effect had worn off, after checking the level of anesthesia and supplementing it with urethane if required (see above).

A glass micropipette filled with $2 \%$ pontamine sky blue in $0.5 \mathrm{M}$ sodium acetate was positioned stereotaxically in the preoptic area. Its tip was bumped to a diameter of $\sim 1 \mu \mathrm{m}$, and the signal was amplified $(10,000$ fold $)$ and filtered $(500-2000 \mathrm{~Hz})$ (Neurolog system; Digitimer). Signals from the micropipette were displayed continuously on an oscilloscope, and action potentials of neurons that passed a selected threshold voltage were discriminated and counted in $10 \mathrm{~s}$ bins using a computer-based analysis system (CED POWER1401 and Spike 2 software; Cambridge Electronic Design). In 29 of the 30 rats, the frontal electroencephalogram (EEG) was recorded from two stainless screws implanted bilaterally through the frontal bone. Wires were attached and covered with dental cement (Reprosil; Dentsply International Inc.), and the signal between them was amplified (1000-fold) and filtered $(1-100 \mathrm{~Hz})$. Digital filters in Spike2 were then used to reduce the bandpass to $1-4 \mathrm{~Hz}$.

Preoptic neurons projecting to the medullary raphé were first identified by their antidromic responses to electrical stimulation in the medullary raphé. The search stimuli used were $0.1 \mathrm{~ms}$ square pulses of amplitude $10-70 \mathrm{~V}$, delivered repeatedly at $1.025 \mathrm{~Hz}$. Brief stimulations at $10.25 \mathrm{~Hz}$ were also used to test frequency following as a primary screen for antidromic activation. Neurons that followed stimulation at constant latency were investigated further, whether or not they showed any spontaneous activity. The antidromic threshold of the neuron and its absolute refractory period to paired stimuli were then determined. Finally, antidromic activation was confirmed by the time-controlled collision test (Lipski, 1981). This required the neuron to show ongoing activity, either spontaneous or in response to skin cooling (see Results).

Raphé-projecting preoptic neurons were then tested for thermal sensitivity. Brief skin cooling was performed by circulating cold water through the water jacket for 30-60 s. Skin cooling was tested at least twice for each unit reported. The fall in rectal temperature after two to six repeated episodes of skin cooling was used to assess the response of the unit to core temperature (see Results). In each rat, one to three raphé- projecting preoptic neurons were recorded. At the end of each unit recording, the tip of micropipette was marked by iontophoresis of pontamine sky blue (5 $\mathrm{A}$ cathodal current for $10 \mathrm{~min}$ ).

\section{Tail sympathetic nerve fiber recording}

In an additional 31 rats, postganglionic sympathetic nerve activity (SNA) was recorded from the rat tail lateral collector nerve, which was exposed by removing the skin over the lateral vein (Owens et al., 2002). A pool filled with liquid paraffin was constructed around the tail. Connective tissue was removed from a branch of the nerve trunk, which was then desheathed. Nerve filaments were placed over a silver-wire hook electrode, and few fiber spike activity was recorded differentially with respect to a nearby thread of connective tissue, amplified (10,000 fold), and filtered $(30-600 \mathrm{~Hz})$. The activity was monitored continuously using an oscilloscope and recorded using CED and Spike2 at a sampling rate of 5 $\mathrm{kHz}$. Spikes that passed across a selected threshold voltage were detected with a time-window discriminator and counted as spikes per $10 \mathrm{~s}$ for online reference. Each single unit was discriminated offline using a computer-based spike shape analysis system (Spike 2).

Tail SNA was identified functionally by the excitatory response to passing cold water through the water jacket for 30-60 s. This stimulus was repeated at intervals through the experiment. With the exception of one experimental series ("cold baseline series," detailed at the end of the following paragraph), all subsequent experiments involving brain microinjections were made from warm baseline conditions at which tail SNA was low and stable. To identify brain injection sites, either $1 \%$ red or $2 \%$ yellow-green fluorescent microspheres (FluoSpheres; Invitrogen) was added to the injectate. At the end of experiment, hexamethonium chloride $(50 \mathrm{mg} / \mathrm{kg}$ in saline; Sigma) was given intravenously to confirm that the recorded activity was postganglionic sympathetic.

Bicuculline microinjection into the preoptic area. In 15 rats, the effect of disinhibition of neurons in the preoptic area on tail SNA was tested by microinjection of $\mathrm{GABA}_{\mathrm{A}}$ receptor antagonist bicuculline methiodide. In this experimental series, a glass micropipette (tip outer diameter, $\sim 20$ $\mu \mathrm{m}$ ) was aimed sequentially at the RMPO and CLPO (Tanaka et al., 2009). Pipettes were finely positioned in those regions by locating the sites where microinjections of GABA $(300 \mathrm{~mm}$ in distilled water, $30 \mathrm{nl}$; Sigma) excited tail SNA (Tanaka et al., 2009). Microinjections were made using air pressure (Neuro Phore BH-2; Medical Systems) and were monitored by observing the meniscus through a dissecting microscope. Once the GABA-responsive site had been identified, the pipette was removed from the brain, refilled with artificial CSF (aCSF) or (-)-bicuculline methiodide (0.5 mM in aCSF; Sigma), and lowered into the same position. Artificial CSF consisted of $128 \mathrm{~mm} \mathrm{NaCl}, 2.6 \mathrm{~mm} \mathrm{KCl}, 1.3 \mathrm{mM} \mathrm{CaCl}_{2}$, $0.9 \mathrm{~mm} \mathrm{MgCl}_{2}, 20 \mathrm{mM} \mathrm{NaHCO}_{3}$ and $1.3 \mathrm{mM} \mathrm{Na}_{2} \mathrm{HPO}_{4}$. In nine rats, bicuculline and aCSF were microinjected in volumes of 15 and $30 \mathrm{nl}$, respectively. The pipette was flushed with aCSF at least twice whenever the injectate was changed. In another six rats (cold baseline series), a single $60 \mathrm{~s}$ cooling episode starting from warm baseline conditions was used to activate tail sympathetic fibers. Against this background, unilateral microinjections were made only into the CLPO (for explanation, see Results) starting 5 min after the cooling episode was completed.

Kynurenate microinjection into the medullary raphé. The glutamate receptor antagonist kynurenic acid (kynurenate; Sigma) was dissolved in hypotonic aCSF with $10 \mathrm{M} \mathrm{NaOH}$, and then the $\mathrm{pH}$ was adjusted to $\sim 7.4$ by adding $1 \mathrm{M} \mathrm{HCl}$. Hypotonic aCSF consisted of $103 \mathrm{~mm} \mathrm{NaCl}, 2.6 \mathrm{~mm}$ $\mathrm{KCl}, 1.3 \mathrm{~mm} \mathrm{CaCl}_{2}, 0.9 \mathrm{~mm} \mathrm{MgCl}_{2}, 20 \mathrm{~mm} \mathrm{NaHCO}_{3}$ and $1.3 \mathrm{~mm}$ $\mathrm{Na}_{2} \mathrm{HPO}_{4}$, calculated to make the kynurenate solution approximately isotonic. A glass micropipette was filled with $50 \mathrm{~mm}$ sodium glutamate (in aCSF; Sigma), positioned stereotaxically into the rostral medulla (3.0 $\mathrm{mm}$ posterior to lambda, $0.0-0.5 \mathrm{~mm}$ lateral to midline, and $9.5 \mathrm{~mm}$ deep to the dural surface) according to the brain atlas of Paxinos and Watson (1998) and aimed at the ventral medullary raphé. Its appropriate location was confirmed by excitation of tail SNA by injecting 15-30 $\mathrm{nl}$ of glutamate (Tanaka and McAllen, 2005) (data not shown). It was then withdrawn and the solution replaced with aCSF or $50 \mathrm{~mm}$ kynurenate before it was reinserted to the original position.

In six rats, $15 \mathrm{nl}$ of $0.5 \mathrm{~mm}$ bicuculline was first injected into the RMPO with a second glass micropipette, as described above. In this experimental 

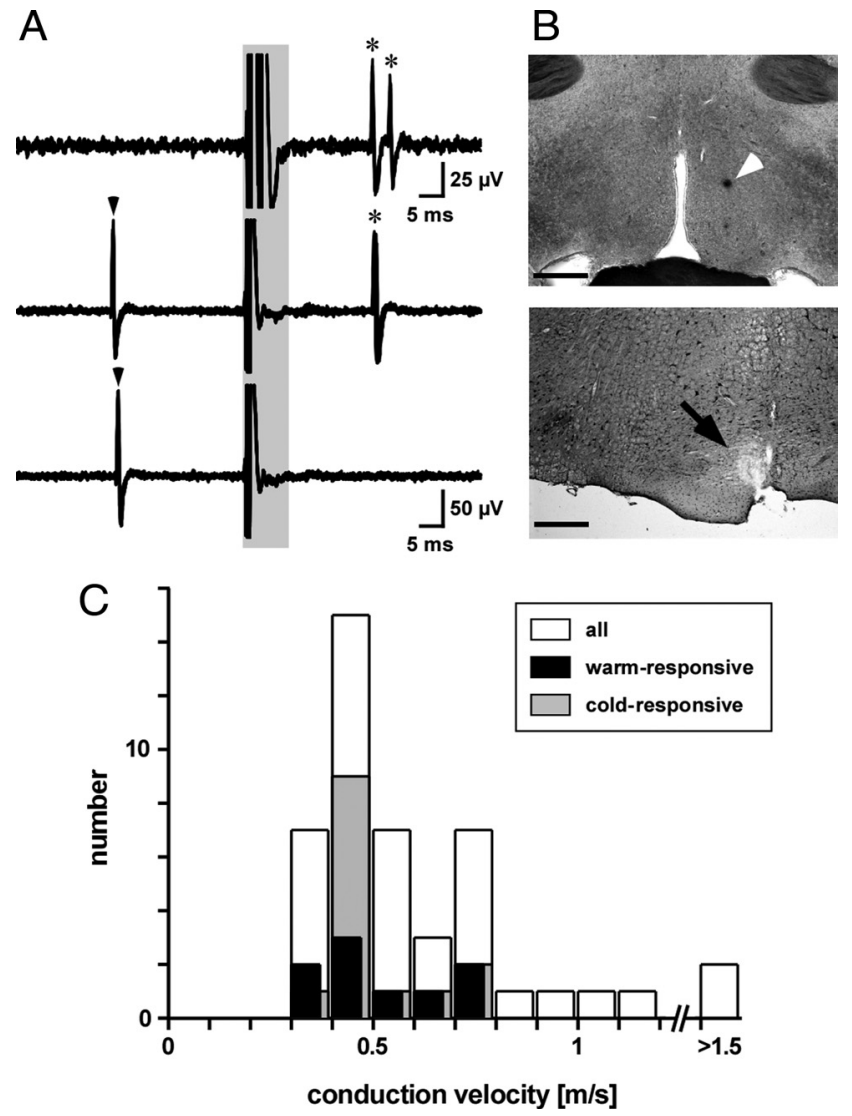

Figure 1. Identification of raphé-projecting preoptic neurons. $A$, Recordings showing antidromic responses of a preoptic neuron to raphé stimulation. Each trace shows five superimposed sweeps. Shaded area includes artifacts from electrical stimuli delivered to the medullary raphé. Top trace, Constant latency antidromic action potentials (asterisked) to paired stimuli separated by $3 \mathrm{~ms}$. Middle and bottom traces show collision testing. A spontaneous spike (marked by arrowhead) triggered the raphé stimulus after a delay of $26 \mathrm{~ms}$ (middle trace, no collision) or $25 \mathrm{~ms}$ (bottom trace, collision). $\boldsymbol{B}$, Photographs showing preoptic recording site (top, arrowhead) and raphé stimulation site (bottom, arrow). Scale bars, $0.5 \mathrm{~mm}$. C, Histogram showing conduction velocities of 45 raphé-projecting preoptic neurons (white), including nine that were inhibited by cooling (warm-responsive, black) and 14 were activated by cooling (cold-responsive, gray).

series, only the RMPO was tested (for explanation, see Results). Subsequent injections of kynurenate or vehicle (aCSF) were made into the medullary raphé in volumes of $120 \mathrm{nl}$ over $60 \mathrm{~s}$, starting 2 min after the preoptic bicuculline injection.

In seven other rats, a single 60-70 s cooling episode starting from warm baseline conditions was used to activate tail SNA. After tail SNA, skin, and core temperatures had returned to their baseline values, either vehicle (aCSF) or $50 \mathrm{~mm}$ kynurenate were injected into the medullary raphé in volumes of $120 \mathrm{nl}$. After an interval of at least $2 \mathrm{~min}$ to check that kynurenate had not changed baseline conditions, the same cooling protocol was repeated.

Electrical stimulation of the preoptic area and medullary raphé. In five rats, including two rats in which bicuculline had been injected into the CLPO, electrical stimuli were delivered to both the RMPO and the medullary raphé, using lacquer-insulated stainless steel monopolar electrodes. The stimuli used were four pulses of $0.5 \mathrm{~ms}$ square pulses $(3 \mathrm{~ms}$ intervals), with current of $0.5 \mathrm{~mA}$ (raphé) and 0.75-1.5 mA (RMPO), delivered every $2-3 \mathrm{~s}$. The tail SNA response to these stimuli was measured. At the end of stimulation, the tip of stimulating electrode was marked by depositing iron ( $25 \mu \mathrm{A}$ anodal current for $30-45 \mathrm{~s})$ for subsequent detection by Perl's Prussian Blue stain.

At the end of experiments, animals were deeply anesthetized with pentobarbital sodium (325 mg, i.v.) and perfused transcardially with saline followed by $4 \%$ paraformaldehyde. The brain was removed and

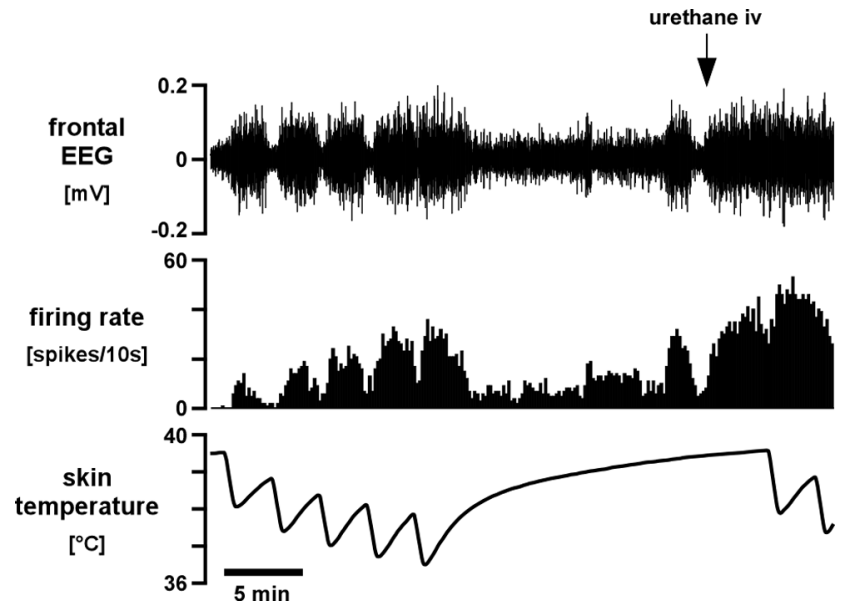

Figure 2. Example of an EEG-related raphé-projecting preoptic neuron. Traces (from the top) show filtered frontal EEG (bandpass, 1-4 Hz), neuron firing rate (10 s counts), and skin temperature. At the start of the trace, the neuron and the EEG respond together to skin cooling. Toward the end of the trace, the neuron continues to follow the EEG but shows changes unrelated to skin temperature. A supplemental dose of urethane ( $25 \mathrm{mg}$, at arrow) synchronized the EEG and dissociated the activity of the neuron from skin temperature.

placed in the same fixative at least overnight. After cryoprotection with $20 \%$ sucrose in PBS, $40 \mu \mathrm{m}$ frozen coronal sections were made of the preoptic area and the medullary raphé. Using fluorescence microscopy (Axioplan 2 imaging; Carl Zeiss), the locations of injection sites and simulating electrodes in tail SNA recording experiment were identified by detecting fluorescent microspheres and iron, respectively, whereas the locations of unit recording and stimulating electrode in single-unit recording experiments were identified by detecting pontamine sky blue and electrode tracks, respectively. Relevant sections were photographed under both light and fluorescence optics using a digital camera (AxioCam HRc; Carl Zeiss). Anatomical detail was revealed by contrast reversal of the light microscopic image in Adobe Photoshop. All stimulation, recording and microinjection sites were identified and mapped in relation to local structures on a set of drawings made from serial coronal sections of the preoptic area and medulla. Their exact rostrocaudal and mediolateral positions over the preoptic area were then calculated and reconstructed in the horizontal plane, measuring distances rostrocaudally from the front of the junction of the anterior commissure and laterally from the wall of the third ventricle.

\section{Statistical analysis}

Raphé-projecting preoptic neuron recording. The resting core temperature, skin temperature, and firing rate of raphé-projecting preoptic neuron (spikes/10 s) were measured as the average values of these variables over 1 min just before stimulation.

To test objectively whether a raphé-projecting preoptic neuron responded to skin cooling, the moving $F$ statistic method (Riffenburgh and Cummins, 2006) was used to detect any change in firing rate. For this purpose, the responses of each neuron to all cooling episodes were averaged from $60 \mathrm{~s}$ before until $120 \mathrm{~s}$ after the onset of skin cooling. The moving $F$ statistic was calculated every $10 \mathrm{~s}$ from a moving sample of three $10 \mathrm{~s}$ mean values. A significant change in the time series was detected when the moving $F$ value exceeded 5.786, indicating $p<0.05$ (Riffenburgh and Cummins, 2006). The $10 \mathrm{~s}$ mean firing rate, averaged over all cooling episodes, was then plotted against the averaged skin temperature. The regression line of this plot was used to measure the responsiveness of the neuron to skin temperature. The threshold temperature of the response to skin cooling of each neuron was estimated from the first cooling episode, using the time point when the moving $F$ statistic first detected a significant change. In two cases in which the first cool yielded no significant change, threshold was estimated from the second cool. To determine whether core temperature affected the activity of a neuron, firing rates were measured from the rewarming phase after each cooling episode, at times when skin temperature had recovered to a 
A
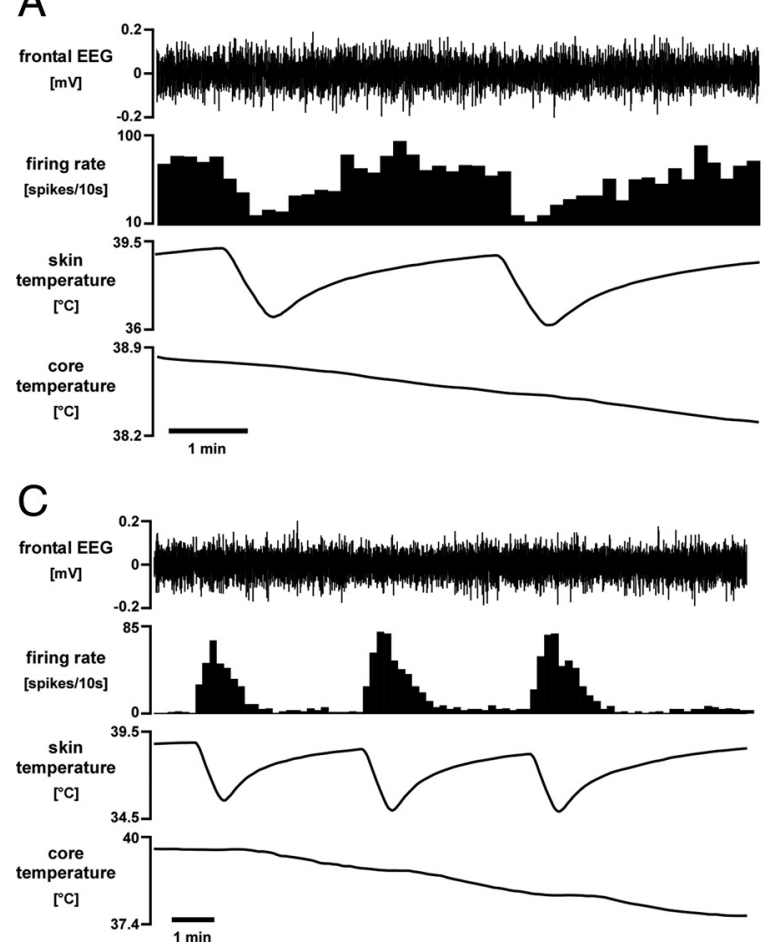

B

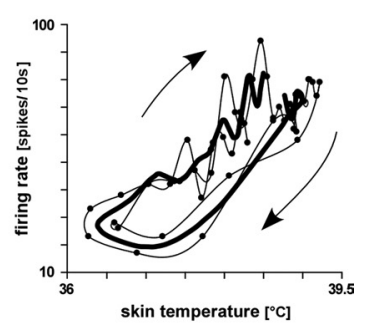

$\mathrm{D}$

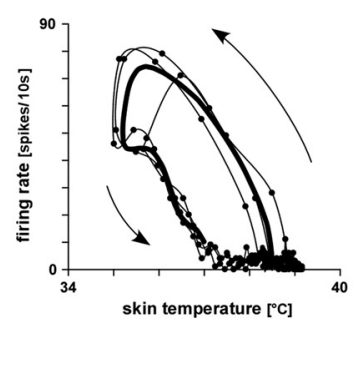

Figure 3. Temperature-responsive raphé-projecting preoptic neurons. $\boldsymbol{A}$, Representative chart record showing reduced activity of a warm-responsive raphé-projecting preoptic neuron in response to skin cooling, whereas the filtered EEG was unchanged. Traces (from top) show filtered frontal EEG (bandpass, 1-4 Hz), neuron firing rate (10 s counts), and skin and core (rectal) temperatures. $\boldsymbol{B}$, Plot of the activity of that neuron versus skin temperature (2 cycles, average shown by thick line, sequence indicated by arrows). $C$, Chart record showing the excitatory response to skin cooling of a cold-responsive raphé-projecting preoptic neuron, whereas the EEG was unchanged. Traces are as in $\boldsymbol{A}$. D shows the corresponding plot (three cooling cycles) of activity versus skin temperature (details as for $\boldsymbol{B}$ ).

set level (see Results). The firing rate of the neuron at each of these times was then plotted against the prevailing core temperature, to obtain the regression line describing its sensitivity to core temperature.

Tail sympathetic nerve fiber recording. The resting core temperature, skin temperature, blood pressure, heart rate, expired $\mathrm{CO}_{2}$, and few-fiber tail SNA (spikes/10 s) were measured as the average values of these variables over 2 min just before each stimulation.

After bicuculline microinjections into the preoptic area, responses were measured as the mean values from 1-3 min (tail SNA and blood pressure), 3-5 min (heart rate and expired $\mathrm{CO}_{2}$ ), and 5-7 min (core temperature) after the injection. These delays were chosen to match the characteristic latency of each response. The values at those times were compared with baseline values, using Student's paired $t$ test to determine significant changes. To assess whether bicuculline injected unilaterally into the CLPO affected cold-evoked tail SNA, averaged tail SNA taken from 1-3 min after the injection was compared with that of a $2 \mathrm{~min}$ period just before the injection, using Student's paired $t$ test.

To assess the effect of kynurenate injection into the medullary raphé on the response to bicuculline injection into the RMPO, tail SNA was measured as $10 \mathrm{~s}$ spike counts averaged over 1 min periods, (1) 1-2 min after the completion of the RMPO bicuculline injection (before raphe injection) and (2) 1-2 min after the completion of the subsequent raphé injection; Student's paired $t$ test was used to detect significant changes. Averaged core temperature 2-4 min after the raphé injection was compared with basal core temperature before RMPO bicuculline injection, using Student's paired $t$ test.

To assess whether kynurenate injection into the medullary raphé affected the tail SNA response to the cooling protocol, tail SNA was measured (1) at the nadir of skin temperature (30 s average) and (2) at the secondary peak of activity that reflects core cooling ( $2 \mathrm{~min}$ average) (Owens et al., 2002). One-way repeated-measures ANOVA, followed by Tukey's test, was used to compare tail SNA response at each time period between three groups: control (without injection), vehicle (aCSF), and kynurenate injections. Baseline tail SNA, skin temperature, core temperature before skin cooling, and the fall in skin temperature were also compared between groups using one-way repeated-measures ANOVA. To assess whether kynurenate injected into the medullary raphé alone affected tail SNA, a 2 min average of tail SNA immediately after kynurenate injection was compared with 2 min just before the injection, using Student's paired $t$ test.

The latencies of tail SNA responses to electrical stimulation were determined from poststimulus histograms of tail SNA (100 sweeps, 5 ms bins) using the moving $F$ statistic method. The moving $F$ statistic was calculated every 5 $\mathrm{ms}$ from a moving sample of five $5 \mathrm{~ms}$ mean values, starting $50 \mathrm{~ms}$ before the stimulus. A significant change in the time series was detected when the moving $F$ value exceeded 6.42, indicating $p<0.01$.

All values were shown as mean $\pm \mathrm{SE}$, and $p<0.05$ was considered significant.

\section{Results}

\section{Raphé-projecting preoptic} neuron recording

The activity of single neurons was recorded extracellularly from the preoptic area in 30 rats. Forty-five preoptic neurons projecting to the medullary raphé were identified by their antidromic response to electrical stimulation of the medullary raphé and confirmed by the collision test (Fig. 1A). Their calculated conduction velocities ranged from 0.3 to

\section{$2.3 \mathrm{~m} / \mathrm{s}$ (median, $0.5 \mathrm{~m} / \mathrm{s} ; n=45$ ) (Fig. $1 C$ ).}

All 45 raphé-projecting preoptic neurons were tested for their response to repeated skin cooling sequences starting from a warm baseline (skin temperature, $39.7 \pm 0.1^{\circ} \mathrm{C}$; core temperature, $\left.38.3 \pm 0.1^{\circ} \mathrm{C} ; n=45\right)$, by circulating cold water through the jacket surrounding the shaved trunk. Each skin cooling episode of $30-60 \mathrm{~s}$ lowered skin temperature by $2.3 \pm 0.05^{\circ} \mathrm{C}$ (range, $1.3-4.2^{\circ} \mathrm{C}$ ). Even in well-anesthetized rats, changes in skin temperature may change the EEG state, which in turn may affect the firing of preoptic and other neurons (Kanosue et al., 1985; Grahn and Heller, 1989; Grahn et al., 1989; Berner and Heller, 1998). To distinguish neurons that responded primarily to the EEG from those that responded primarily to skin temperature, we recorded the frontal EEG. Four raphé-projecting preoptic neurons showed activity closely linked to the low-frequency component $(1-4 \mathrm{~Hz})$ of the frontal EEG, regardless of changes in skin temperature ("EEG-related neurons") (Fig. 2). The activity of 39 other raphéprojecting preoptic neurons was independent of the EEG state, although in six cases, skin cooling caused a decrease in the lowfrequency component of the EEG (desynchronization). Eighteen of those 39 neurons did not change their firing rate when the trunk skin was cooled ("thermo-insensitive neurons"), 14 neurons were excited ("cold-responsive neurons"), and seven were inhibited. We refer to the latter as "warm-responsive neurons." An additional two warm-responsive raphé-projecting preoptic neurons were recorded in the absence of an EEG recording. The averaged antidromic latencies of warm- and cold-responsive 
neurons were $23 \pm 2 \mathrm{~ms}$ (range, $15-35 \mathrm{~ms}$; $n=9$ ) and $24 \pm 1 \mathrm{~ms}$ (range, 15-31 ms; $n=14)$, respectively.

\section{Warm-responsive}

raphé-projecting neurons

Warm-responsive neurons showed spontaneous activity under warm baseline conditions $(75 \pm 19$ spikes/10 s; skin temperature, $40.0 \pm 0.1^{\circ} \mathrm{C}$; core temperature, $\left.38.8 \pm 0.1^{\circ} \mathrm{C} ; n=9\right)$. Once the trunk skin was cooled, warmresponsive neurons significantly decreased their firing rate before there was any fall in core temperature (Fig. $3 A$ ). Each warm-responsive neuron responded consistently to repeated skin cooling episodes (two to three in each case). The threshold skin temperature for a response to cooling was $39.3 \pm$ $0.3^{\circ} \mathrm{C}(n=9)$. The response usually showed hysteresis: cool temperatures inhibited neurons more effectively when skin temperature was falling than when it was rising (Fig. 3B), and firing began to recover immediately after skin temperature stopped falling. The mean fall in activity during skin cooling was $2.1 \pm 0.5$ spikes $/ \mathrm{s} /{ }^{\circ} \mathrm{C}$ (range, $0.3-4.8$ spikes $/ \mathrm{s} /{ }^{\circ} \mathrm{C} ; n=9$ ).

Cold-responsive raphé-projecting neurons Cold-responsive neurons showed little or no activity under baseline warm conditions ( $2 \pm 1$ spikes/10 s; skin temperature, $39.4 \pm 0.1^{\circ} \mathrm{C}$; core temperature, $38.2 \pm$ $\left.0.2^{\circ} \mathrm{C} ; n=14\right)$. Brief skin cooling episodes induced robust, reproducible increases in the firing rate of these neurons (Fig. 3C). In 12 of 14 cold-responsive neurons, activity increased clearly before any fall in core temperature. The other two neurons were activated only by the second and subsequent skin cooling episodes, after core temperature had fallen slightly (by 0.1 and $0.3^{\circ} \mathrm{C}$ ). The mean threshold skin temperature for activating cold-responsive neurons was $39.0 \pm 0.2^{\circ} \mathrm{C}(n=14)$. All 14 neurons showed hysteresis in their response to skin cooling (Fig. 3D), reflecting a stronger effect of falling than rising skin temperature. Their mean increase in activity with skin cooling was $4.6 \pm 1.3 \mathrm{spikes} / \mathrm{s} /{ }^{\circ} \mathrm{C}$ (range, 0.4 to 18 spikes $/ \mathrm{s} /{ }^{\circ} \mathrm{C} ; n=14$ ).

All neurons were recorded from within or between the two preoptic subregions (RMPO and CLPO) identified by previous work (Tanaka et al., 2009) as containing cells that tonically inhibit the sympathetic outflow to the rat tail vasculature (Fig. 4A-G). Most cold-responsive neurons were in the RMPO, whereas warmresponsive neurons were predominantly in the CLPO. All stimulating electrodes were located in the medullary raphé (Fig. $4 H, I$ ).

\section{Effects of core temperature}

The fall in core temperature that followed skin cooling episodes clearly influenced the firing rates of some raphé-projecting preoptic neurons. Figure 5 shows data from two such neurons, one

G
B

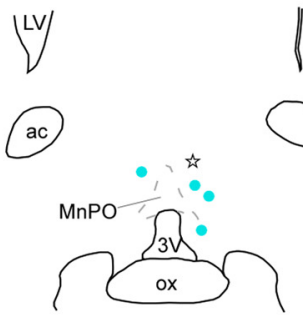

E

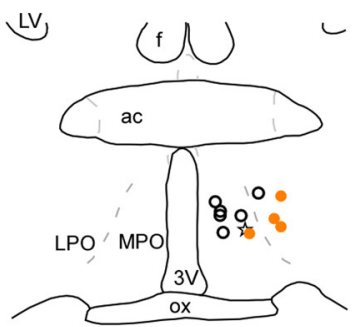

C

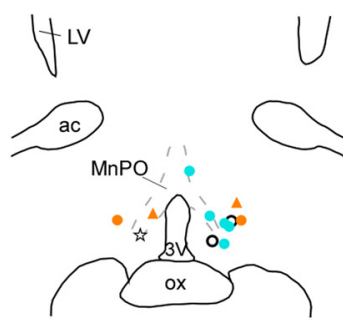

$\mathrm{F}$

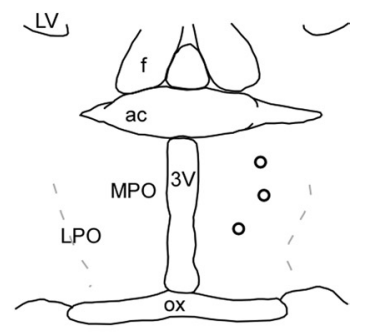

Figure 4. $\quad \boldsymbol{A}-\boldsymbol{F}$, Drawings of coronal sections in rostrocaudal sequence through the preoptic area showing the recording sites of 45 raphé-projecting neurons. Warm-responsive neurons are shown by red dots, cold-responsive neurons by blue dots, thermoinsensitive neurons by white dots, and EEG-related neurons by stars. Two warm-responsive neurons identified without EEG recording are marked by red triangles. G, All recording sites (with corresponding symbols) reconstructed in the horizontal plane. ventricle; ac, anterior commissure; f, fornix; FN, facial nucleus; MPN, medial preoptic nucleus; MP0, medial preoptic area; LPO, lateral preoptic area; LV, lateral ventricle; OVLT, organum vasculosum of the lamina terminalis; ox, optic chiasm; py, pyramidal tract; $\mathrm{RMg}$, raphé magnus nucleus; $\mathrm{RPa}$, raphé pallidus nucleus.

warm-responsive and one cold-responsive. In Figure $5 \mathrm{~A}$, the firing rate of the warm-responsive neuron measured at a fixed skin temperature during rewarming periods fell systematically with core temperature (plotted in Fig. 5C). Similarly, the falling core temperature may be seen to increase the firing rate of the cold-responsive neuron shown in Figure 5, $B$ and $D$. Linear regression analysis showed that four of nine warm-responsive neurons significantly reduced their firing rate as core temperature fell, whereas falls in core temperature significantly increased the firing rate in 3 of 14 cold-responsive neurons. No warm-responsive neuron was excited and no coldresponsive neuron was inhibited by falls in core temperature. The slope of the effect of core temperature on the four warm-responsive neurons was $3.4 \pm 1.2$ spikes $/ \mathrm{s} /{ }^{\circ} \mathrm{C}$ (range, $1.4-6.7$ spikes $/ \mathrm{s} /{ }^{\circ} \mathrm{C} ; n=$ 4) and that for the three cold-responsive neurons was $-4.8 \pm 3.1$ spikes $/ \mathrm{s} /{ }^{\circ} \mathrm{C}$ (range, -0.5 to -10.8 spikes $/ \mathrm{s} /{ }^{\circ} \mathrm{C} ; n=3$ ). 
A

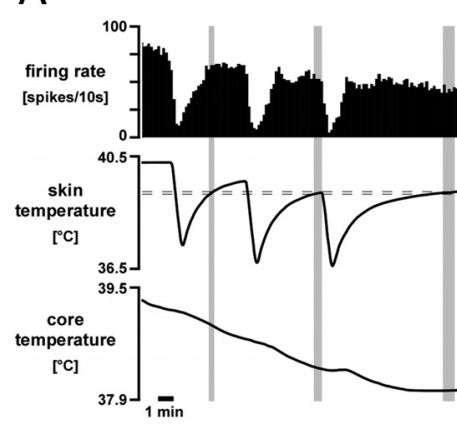

B

C

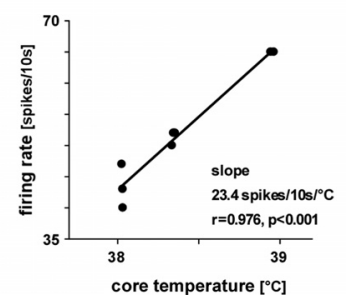

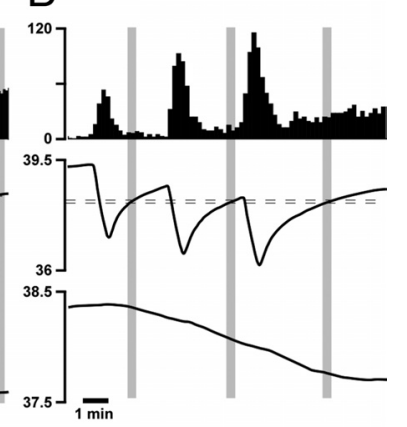

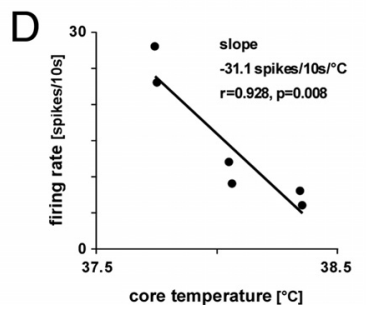

Figure 5. Examples of warm-responsive $(\boldsymbol{A})$ and cold-responsive $(\boldsymbol{B})$ raphé-projecting preoptic neurons that responded also to core temperature. Traces (from top) show neuron firing rate (10 $\mathrm{s}$ counts), skin temperature, and core (rectal) temperature. $($ and $\boldsymbol{D}$ show corresponding plots of their activity versus core temperature, measured during the rewarming phase at times (indicated by shaded areas) when skin temperature had recovered to a set level (indicated by horizontal dashed lines).
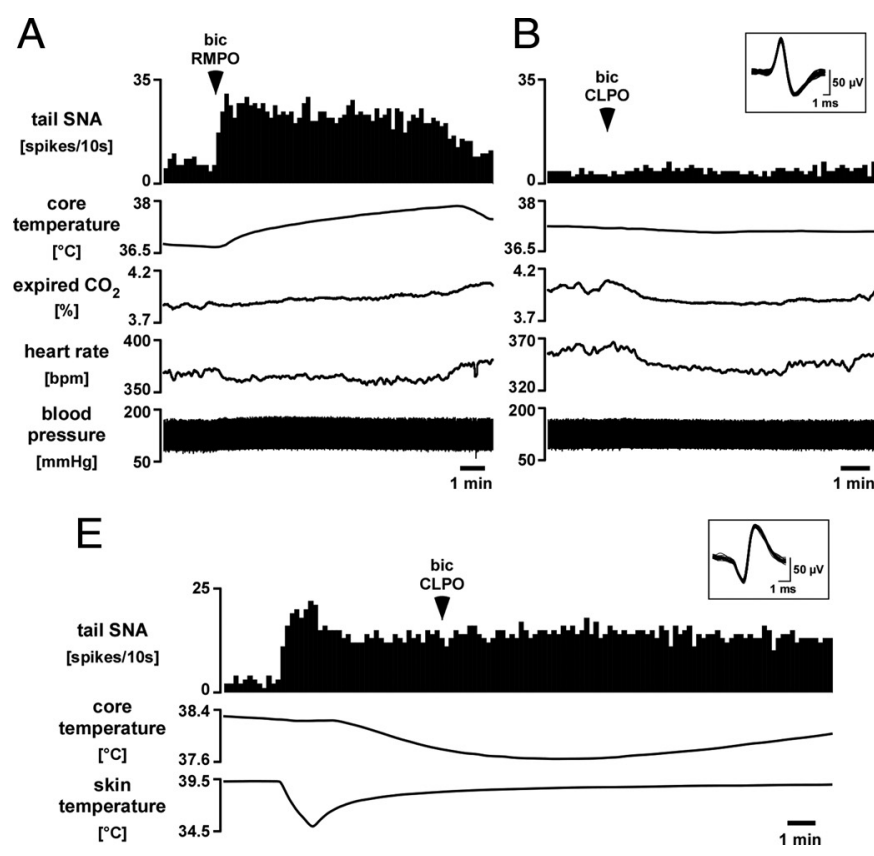

Figure 6. Responses of tail SNA to microinjection of bicuculline into the RMPO and CLPO.A, B, Chart records showing tail SNA responses to microinjection of bicuculline (bic; $0.5 \mathrm{~mm}, 15 \mathrm{nl})$ into the RMPO $(\boldsymbol{A})$ and $\mathrm{CLPO}(\boldsymbol{B})$ in the same animal. Traces from top show single-unit tail SNA (10 s counts), core temperature, peak expired $\mathrm{CO}_{2}$, heart rate, and blood pressure. Superimposed spikes of the tail SNA unit are shown in the inset. Cand $\boldsymbol{D}$ show responses of thetail SNA unit to microinjection of GABA $(300 \mathrm{~mm}, 30 \mathrm{nl})$ into the same RMPO ( $($ and CLPO $(\boldsymbol{D})$ sites. Note that RMPO injections of both bicuculline $(\boldsymbol{A})$ and GABA ( $($ ) excited tail SNA. $\boldsymbol{E}$, Chart record from another experiment showing tail SNA response to an identical injection of bicuculline into the CLPO but at a time when tonic tail SNA had been induced by cooling. Traces from top show single-unit tail SNA (10 s counts), core temperature, and skin temperature. Superimposed tail SNA unit spikes are shown in the inset. The tail SNA response to GABA injected into the same CLPO site is shown in $F$.

Tail sympathetic nerve fiber recording

The currently accepted model of thermoregulation is that both heat production and heat loss are under tonic inhibitory control by warm-sensitive preoptic neurons (Zhang et al., 1995; Chen et
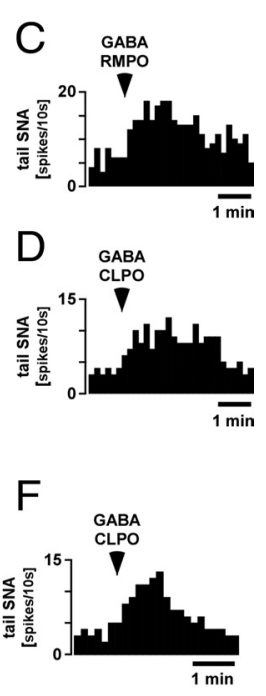

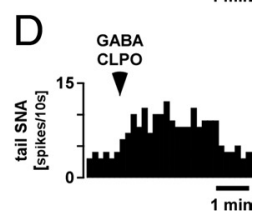

al., 1998; Nagashima et al., 2000; Osaka, 2004; Rathner et al., 2008; Tanaka et al., 2009), with those regulating heat production projecting to the $\mathrm{DMH}$ and those regulating heat dissipation projecting directly to the medullary raphé (Nakamura and Morrison, 07; Morrison et al., 2008; Rathner et al., 2008). No significan excitatory signal from cold-responsive preoptic neurons to the medullary raphé contributes to the thermo-

Microinjection of bicuculline into the preoptic area

On the basis that the proposed preoptic-raphe excitatory pathway may be held inhibited under warm conditions, we microinjected the $\mathrm{GABA}_{\mathrm{A}}$ receptor antagonist bicuculline into the preoptic area to disinhibit those neurons. Microinjections were made into the RMPO of nine of nine rats and into the CLPO of seven of nine rats. In all cases, an appropriate location of the injection pipette was first confirmed by an excitatory response of tail SNA to microinjection of GABA, as described previously Tanaka et al., 2009).

Under warm baseline conditions (skin temperature, $39.8 \pm$ $0.2^{\circ} \mathrm{C}$; core temperature, $38.3 \pm 0.2^{\circ} \mathrm{C}$ ), microinjections of bicuculline $(0.5 \mathrm{mM}, 15 \mathrm{nl})$ into the RMPO produced rapid increases in tail SNA from $5 \pm 1$ to $35 \pm 3$ spikes/10s $(n=9, p<0.01)$. Figure $6 A$ shows an illustrative record. Accompanying the increase in tail SNA were an increase in blood pressure and a delayed rise in core temperature; heart rate and expired $\mathrm{CO}_{2}$ did not change (Figs. 6A, 7). Vehicle injected into the same site in seven of nine rats had no effect on any of these variables (Fig. 7).

In seven rats, microinjections of bicuculline were made into the CLPO. Baseline conditions (skin temperature, $39.4 \pm$ $0.2^{\circ} \mathrm{C}$; core temperature, $37.9 \pm 0.2^{\circ} \mathrm{C}$; tail SNA, $6 \pm 2$ spikes/10 s; $n=7$ ) were similar to those before microinjections into the RMPO $(p>0.05$, unpaired $t$ test). Microinjection of bicuculline into the CLPO caused no significant change in tail SNA, core temperature, or blood pressure (Figs. 6B, 7). Heart rate and expired $\mathrm{CO}_{2}$ both fell slightly, as described previously (Osaka, 2004). Vehicle injected into the same position in the CLPO in six of seven rats had no effect on any of these variables (Fig. 7).

Although bicuculline injected into the GABA-sensitive CLPO region clearly had no excitatory effect on tail SNA, the warm baseline conditions and consequent low tail SNA could have masked an inhibitory action on tail SNA. This is relevant because an inhibitory action from this region on BAT SNA and thermogenesis has been identified (Osaka, 2004; Nakamura and Morrison, 2007). To check for any inhibitory action on tail SNA, the tests were repeated in six additional rats (cold baseline series). In these animals, identical CLPO bicuculline injections were preceded by a 60 s skin cooling episode that lowered skin temperature from 

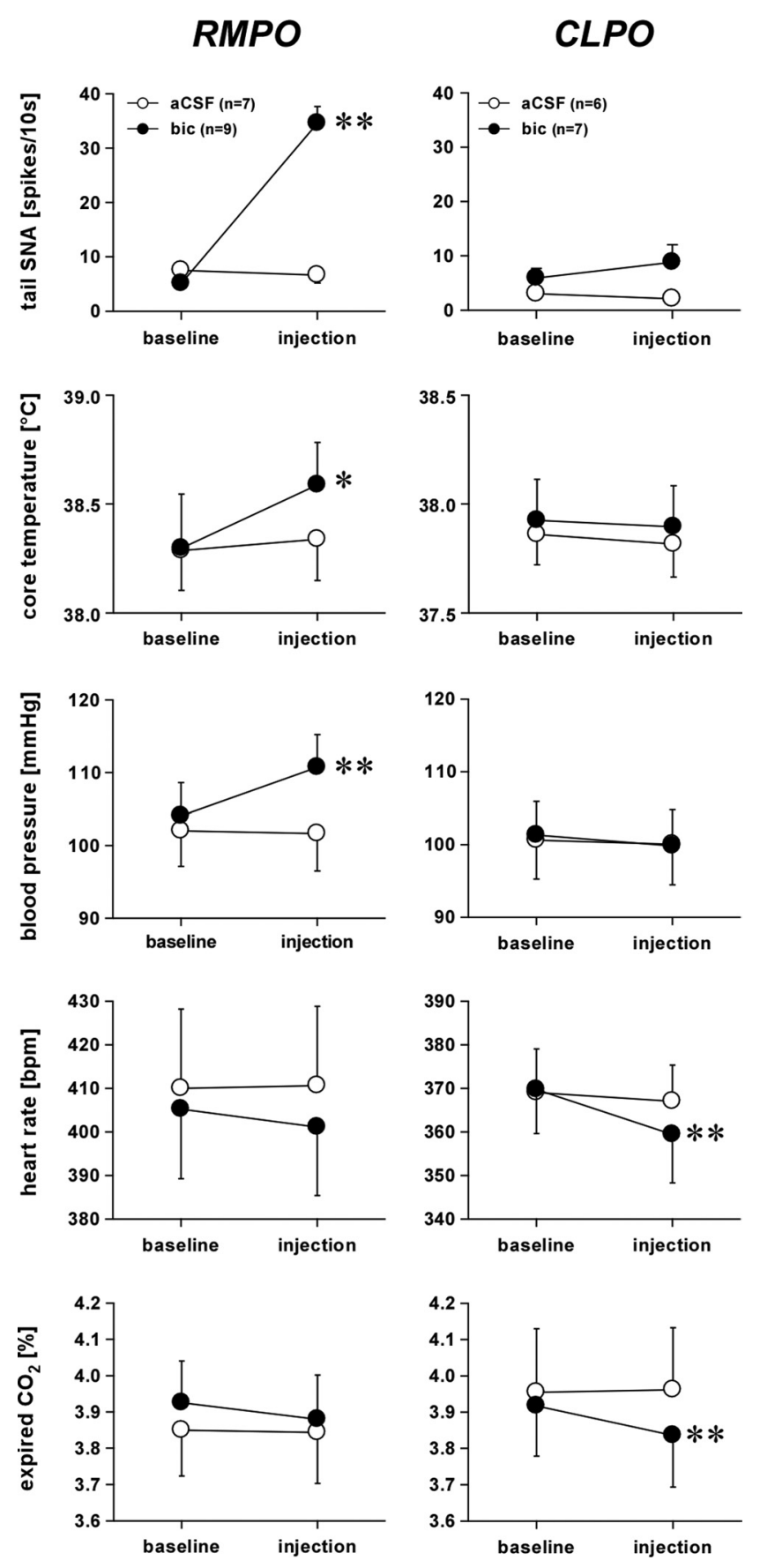

Figure 7. Grouped data from microinjections of bicuculline (bic) into the RMPO (left) and the CLPO (right) under warm baseline conditions. From top to bottom: averaged tail SNA, core temperature, blood pressure, heart rate, and peak expired $\mathrm{CO}_{2}$. Values are given as mean $\pm \mathrm{SE}$. ${ }^{*} p<0.05$ and ${ }^{* *} p<0.01$ compared with baseline.

$39.5 \pm 0.2$ to $35.1 \pm 0.2^{\circ} \mathrm{C}$ and caused tonic firing of tail SNA (Fig. $6 E$ ). Five minutes later, trunk skin temperature was $38.2 \pm$ $0.2^{\circ} \mathrm{C}$, but core temperature had fallen from $38.2 \pm 0.2$ to $37.8 \pm$ $0.2^{\circ} \mathrm{C}$ and tail SNA was stable at $51 \pm 11$ spikes $/ 10 \mathrm{~s}$. Bicuculline was then microinjected unilaterally into the CLPO but had no effect on tail SNA ( $47 \pm 10$ spikes/10 s, $n=6, p>0.05)$ (Fig. $6 E)$.

Microinjections of kynurenate into the medullary raphé

To test whether the tail SNA response to neuronal disinhibition in the RMPO depends on an excitatory synaptic relay in the medullary raphé, the glutamate receptor antagonist kynurenate was
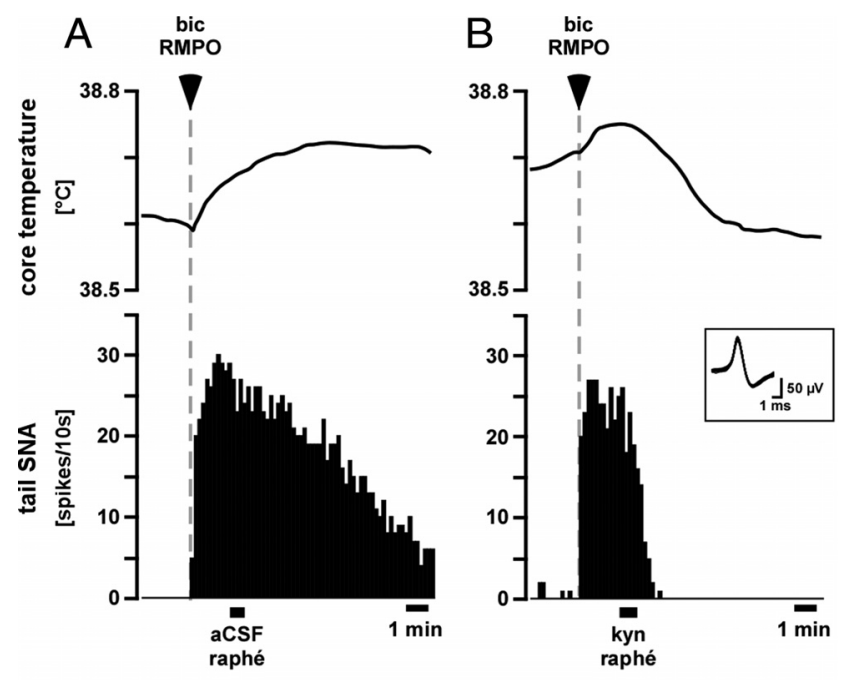

C

D
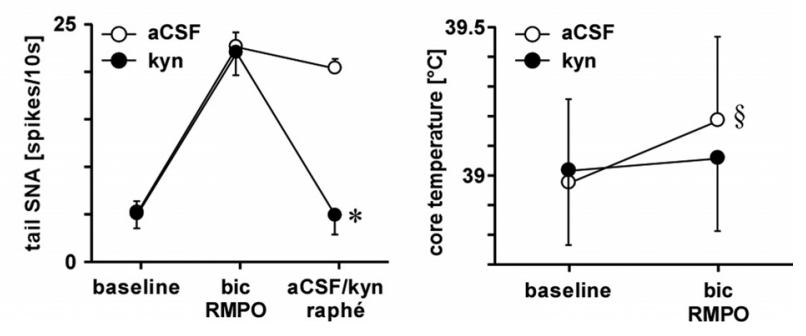

Figure 8. Effect of kynurenate injection into the medullary raphé on tail SNA and core temperature responses to RMPO bicuculline injection. $\boldsymbol{A}, \boldsymbol{B}$, Records from a representative experiment showing core (rectal) temperature (top) and single-unit tail SNA (10 s counts, below) when bicuculline (bic; $0.5 \mathrm{~mm}, 15 \mathrm{nl}$ ) was injected into the RMP0 at the times indicated. Vehicle (aCSF, $120 \mathrm{nl}$ ) or kynurenate $(\mathrm{kyn} ; 50 \mathrm{~mm}, 120 \mathrm{nl}$ ) were then injected into the medullary raphé at the times indicated by bars. Superimposed spikes of the tail SNA unit are shown in the inset. $C$, D, Grouped data from six experiments. ( shows averaged few-fiber tail SNA at baseline, after bicuculline injections into the RMPO and after subsequent injection of vehicle or kynurenate into the medullary raphé. $D$ shows baseline core temperature before RMPO bicuculline injection and the resultant core temperature $2-4 \mathrm{~min}$ after raphé injection. Baseline skin temperatures $\left(39.9 \pm 0.2\right.$ and $40.0 \pm 0.2^{\circ} \mathrm{C}$, respectively) were not different $(p>0.05) .{ }^{*} p<0.01 \mathrm{com}$ pared with the response to bicuculline. ${ }^{\S} p<0.01$ compared with baseline.

injected into the medullary raphé of six rats after bicuculline was injected into the RMPO. Figure 8 shows a representative record. As described above, microinjection of bicuculline into the RMPO produced a rapid increase in tail SNA. Microinjection of vehicle into the medullary raphé $120 \mathrm{~s}$ after the microinjection of bicuculline into the RMPO had no effect on the increase in tail SNA and core temperature (Fig. $8 A, C, D$ ). In contrast, microinjection of kynurenate into the medullary raphé completely reversed the increase in tail SNA and suppressed the rise in core temperature evoked by bicuculline injection (Fig. $8 B-D$ ).

Next, we tested whether an excitatory connection to the medullary raphé, driven by cool skin, had any measurable effect on tail SNA. Figure 9 shows a representative example of effect of kynurenate injection into the medullary raphé on tail SNA response to skin cooling. For this experiment, a standard 60-70 s cooling protocol was used to cause a reproducible profile of tail SNA (Fig. 9A) across three tests in each animal: control (without injection), vehicle, and kynurenate injections. Basal conditions and the falls in skin temperature were not different between the three groups ( $p>0.05, n=7$ ) (Table 1 ). As reported previously (Owens et al., 2002), tail fiber activation by this cooling protocol is attributable to two components: the immediate fall in skin 

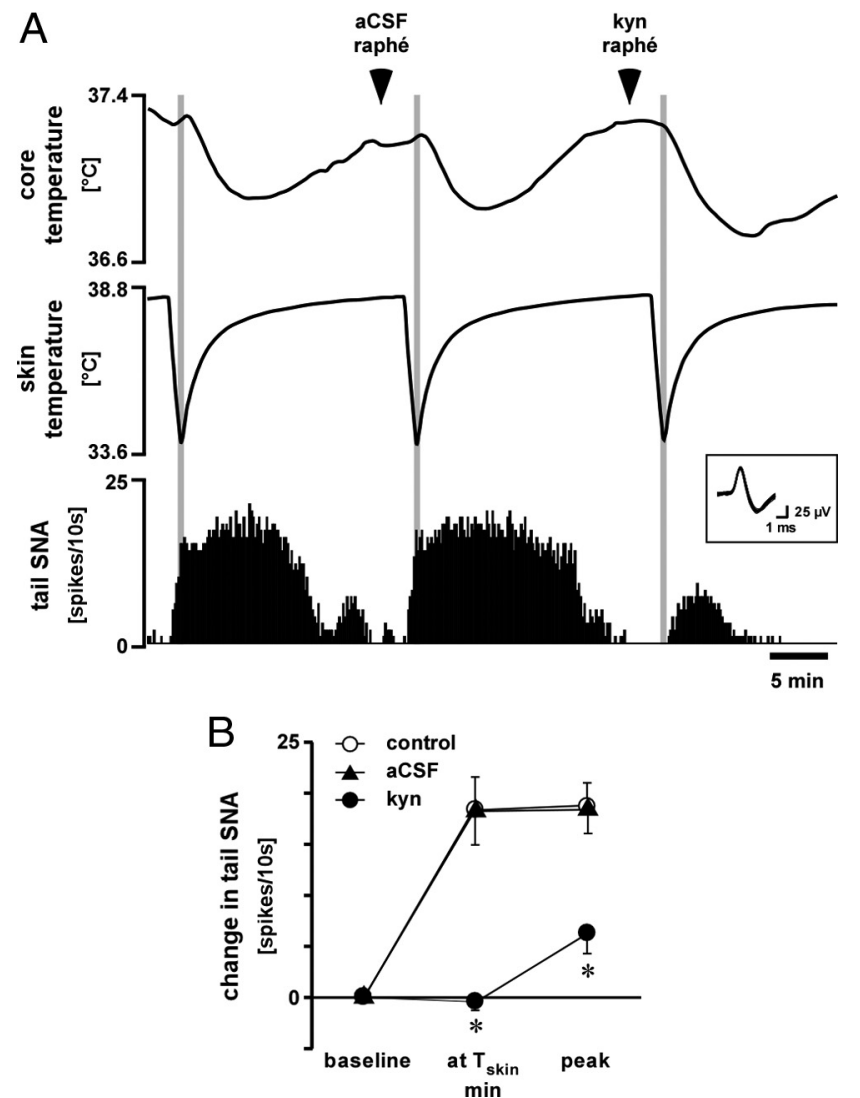

Figure 9. Effect of kynurenate injection into the medullary raphé on tail SNA response to skin cooling. $A$, Representative chart record showing core (rectal) temperature, skin temperature, and single-unit tail SNA (10s counts). Vehicle (aCSF) and kynurenate (kyn; $50 \mathrm{~mm}, 120 \mathrm{nl}$ ) were injected into the medullary raphé at the times indicated. Superimposed spikes of tail SNA are shown in the inset. $\boldsymbol{B}$ shows grouped data $(n=7)$ on the mean few-fiber tail SNA responses to skin cooling when vehicle or kynurenate were injected into the medullary raphé. The three time points represent baseline, the nadir of skin temperature (at $\mathrm{T}_{\text {skin }}$ min, shaded areas in $A$ ), and at the secondary peak of activity that reflects core cooling (peak). ${ }^{*} p<0.01$ compared with control (without injection) at the same time point. Baseline values are given in Table 1.

Table 1. Baseline tail SNA and skin and core temperatures before the skin cooling that followed microinjections into the medullary raphé

\begin{tabular}{lccc}
\hline & Control $(n=7)$ & Vehicle $(n=7)$ & Kynurenate $(n=7)$ \\
\hline Basal tail SNA (spikes $/ 10 \mathrm{~s})$ & $3 \pm 1$ & $2 \pm 1$ & $3 \pm 1$ \\
Basal skin temperature $\left({ }^{\circ} \mathrm{C}\right)$ & $38.9 \pm 0.2$ & $38.9 \pm 0.1$ & $38.8 \pm 0.2$ \\
Basal core temperature $\left({ }^{\circ} \mathrm{C}\right)$ & $37.9 \pm 0.3$ & $37.8 \pm 0.3$ & $37.7 \pm 0.3$ \\
Fall in skin temperature $\left({ }^{\circ} \mathrm{C}\right)$ & $4.2 \pm 0.1$ & $4.3 \pm 0.1$ & $4.3 \pm 0.1$ \\
\hline
\end{tabular}

Baseline values indicate the average values during $2 \mathrm{~min}$ before skin cooling. There was no significant difference between columns for any variables. Values are mean $\pm \mathrm{SE}$.

temperature and the delayed fall in core temperature (Fig. 9). Microinjection of vehicle into the medullary raphé had no effect on the response to the cooling protocol (Fig. 9). Microinjection of kynurenate into the medullary raphé had no effect on baseline tail SNA ( $5 \pm 1$ to $4 \pm 2$ spikes/ $10 \mathrm{~s}, p>0.05, n=7$ ), but it abolished the component of tail SNA attributable to skin cooling (Fig. 9). The component attributed to the fall in core temperature was significantly attenuated by kynurenate compared with the other two groups (Fig. 9).

Electrical stimulation of the preoptic area and the medullary raphé In five rats, the medullary raphé and the RMPO were electrically stimulated, and the latencies to onset of tail SNA response were compared (Fig. 10). Stimulation of the medullary raphé (four
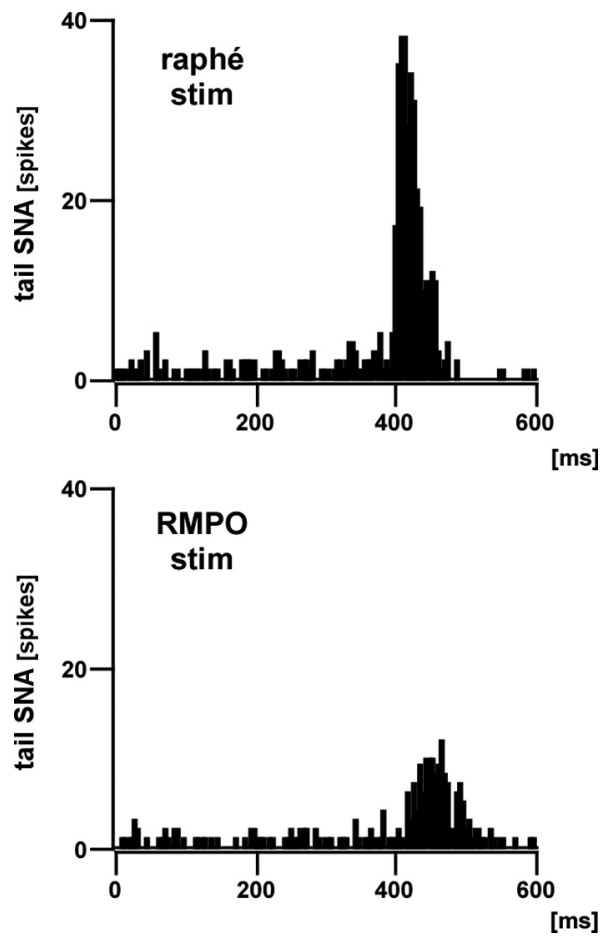

Figure 10. Tail SNA responses to electrical stimulation of the medullary raphé and the RMPO. Representative examples of poststimulus histograms (100 trials, $5 \mathrm{~ms}$ bins) of tail SNA responses to electrical stimulation of the medullary raphé (top) and RMPO (bottom). Electrical stimuli ( $0.5 \mathrm{~ms}$ width, 4 pulses separated by $3 \mathrm{~ms}$ intervals) were delivered at currents of $0.5 \mathrm{~mA}$ (raphé) and $0.75 \mathrm{~mA}$ (RMPO). The onset latencies of tail SNA responses to raphé and RMPO stimuli were 395 and $410 \mathrm{~ms}$, respectively.

pulses, $3 \mathrm{~ms}$ intervals, $0.5 \mathrm{~ms}$ duration, $0.5 \mathrm{~mA}$ ) evoked discharge of the tail sympathetic fibers with an onset latency of $382 \pm 5 \mathrm{~ms}$ $(n=5)$, whereas stimulation of the RMPO (four pulses, $3 \mathrm{~ms}$ intervals, $0.5 \mathrm{~ms}$ duration, $0.75-1.5 \mathrm{~mA}$ ) evoked discharge of the tail sympathetic fibers with an onset latency of $407 \pm 3 \mathrm{~ms}(n=$ $5)$. These two latencies were significantly different ( $p<0.01, n=$ $5)$, and the difference between these two latencies was $25 \pm 4 \mathrm{~ms}$ (range, $15-35 \mathrm{~ms} ; n=5$ ). The stimulation sites are shown in Figure 11 .

\section{Discussion}

Since the discovery of temperature-responsive neurons in the anterior hypothalamus and preoptic area (Nakayama et al., 1961), numerous studies have investigated the characteristics of temperature-sensitive neurons, mostly in brain slices (for references, see Boulant, 2000). No previous investigation has paid attention to their neuronal connections, which is crucial information if their physiological function is to be identified. This is the first electrophysiological study to identify temperatureresponsive preoptic neurons that project directly to the medullary raphé, in which sympathetic premotor neurons controlling cold defense responses such as tail vasoconstriction and BAT thermogenesis are located. Raphé-projecting preoptic neurons that respond to temperature may regulate cutaneous vasoconstriction. It is less likely that they regulate thermogenic mechanisms, whose pathways include an obligatory synaptic relay in the DMH (Madden and Morrison, 2004; Nakamura and Morrison, 2007). It has been observed that some preoptic neurons project to both the medullary raphe and the $\mathrm{DMH}[10-15 \%$ according to Nakamura et al. (2009); "very few" according to Yoshida et al. 
(2009)], so a contribution to thermogenesis by raphé-projecting preoptic neurons is not entirely ruled out.

Finding warm-responsive raphéprojecting preoptic neurons in this study was expected on the basis of previous evidence, but finding cold-responsive neurons there was unexpected and novel. Follow-up experiments demonstrated that an excitatory pathway from the RMPO (but not the CLPO) to the medullary raphé exists alongside the previously demonstrated inhibitory pathway, and both regulate tail SNA. An excitatory projection to the medullary raphé was shown to be responsible for conveying the signal from cold skin to drive tail SNA, and cold-responsive raphé-projecting preoptic neurons are likely candidates to mediate this action.

\section{Temperature responsive}

raphé-projecting preoptic neurons

Skin cooling performed in this study was within the non-noxious range (Defrin et al., 2002), and most recorded neurons were independent of EEG state, suggesting that their responses were attributable simply to skin temperature rather than to nociceptive signals or a change in arousal state. The activity patterns of warm- and cold-responsive raphé-projecting preoptic neurons mirror those of warm and cold thermosensory afferents. Cutaneous warm receptors show ongoing activity at $\sim 40^{\circ} \mathrm{C}$, at which temperature cutaneous cold receptors are silent. Both cutaneous warm and cold receptors show a high dynamic response to changes in temperature, with lower static sensitivity (Darian-Smith et al., 1973; Hellon et al., 1975; Duclaux and Kenshalo, 1980; Spray, 1986). These firing patterns are mirrored in the second-order dorsal horn neurons (Hellon and Misra, 1973; Andrew and Craig, 2001; Craig et al., 2001) and the third-order neurons in the lateral parabrachial nucleus that provide synaptic projections to the preoptic area (Nakamura and Morrison, 2008a, 2010). Raphé-projecting warm-responsive neurons also showed ongoing activity under warm conditions, whereas the cold-responsive neurons were silent. Both showed strong dynamic responses to skin cooling, with hysteresis on rewarming. This could have resulted from activation of cutaneous cold receptors, inhibition of cutaneous warm receptors, or both. In each case, there would have been a strong dynamic response to rapid skin cooling.

Some raphé-projecting preoptic neurons responded to falls in core temperature as well as skin temperature. This feature was more prevalent among the warm-responsive neuron population. The present data do not tell us whether those cells directly sensed local brain temperature (Magoun et al., 1938; Hammel et al., 1960;

D

$\mathrm{F}$
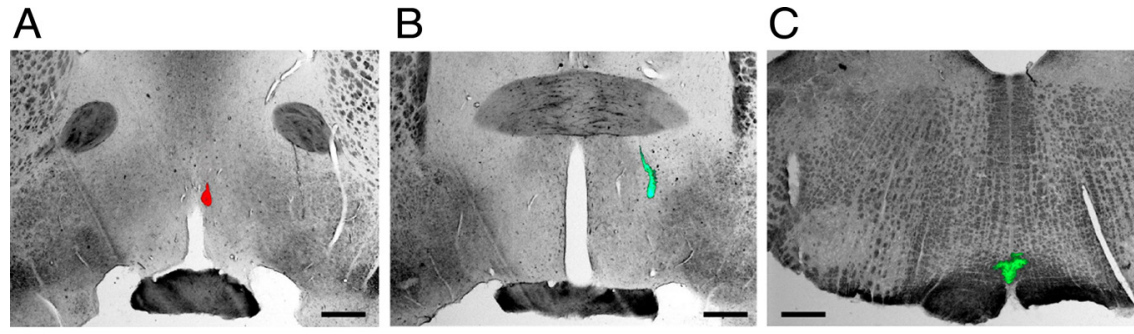

E
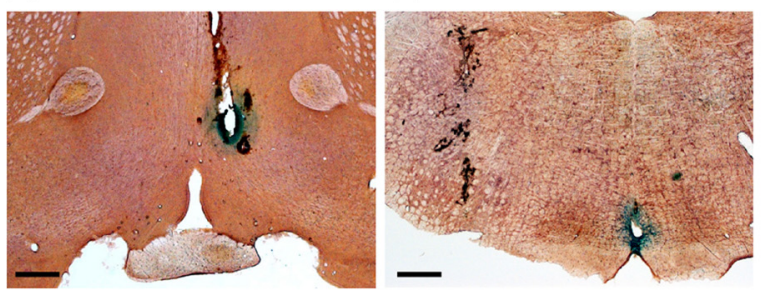

G
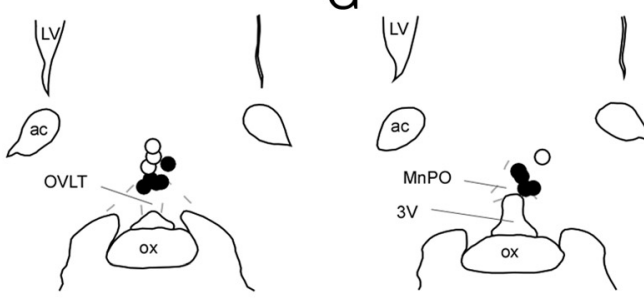

$\mathrm{H}$

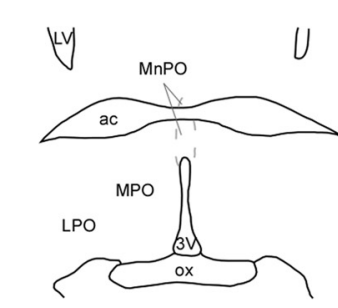

$J$

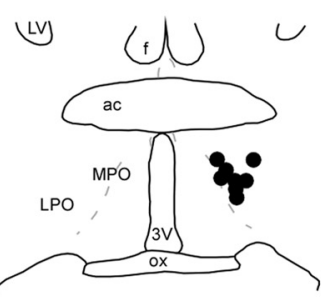

$\mathrm{K}$
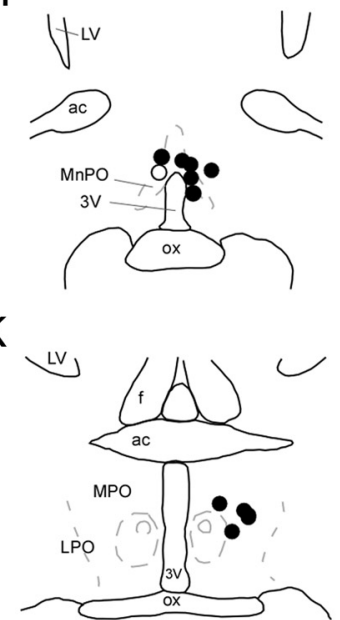

$\mathrm{N}$

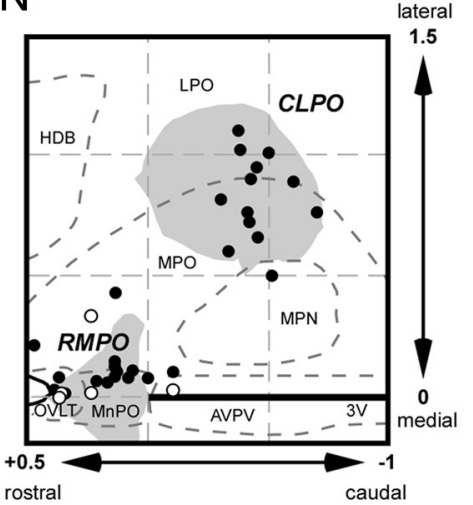

Figure 11. Locations of injection and electrical stimulation sites. $\boldsymbol{A}-\boldsymbol{C}$, Representative photomicrographs of injection sites in the RMPO $(\boldsymbol{A})$, CLPO $(\boldsymbol{B})$, and medullary raphé $(\boldsymbol{C})$. $\boldsymbol{D}$ and $\boldsymbol{E}$ show examples of electrical stimulation sites (marked by Prussian Blue reaction) in the RMPO $(\boldsymbol{D})$ and the medullary raphé $(\boldsymbol{E})$. Scale bars, $0.5 \mathrm{~mm}$. $\boldsymbol{F}-\boldsymbol{M}$, All injection and stimulation sites shown in coronal sections (from rostral to caudal) of the preoptic area $(\boldsymbol{F}-\boldsymbol{K})$ and the medullary raphé $(\boldsymbol{L}, \boldsymbol{M})$. Injection and stimulation sites are indicated by filled circles and open circles, respectively. $\boldsymbol{N}$, All preoptic injection and stimulation sites are reconstructed with corresponding symbols in the horizontal plane, in which the RMPO and CLPO are shown by shaded areas. Abbreviations as in Figure 4.

Zhang et al., 1995; Tanaka et al., 2002) or whether they received core temperature information from other preoptic neurons and/or indirectly from thermosensory (e.g., abdominal) afferents (Riedel, 1976; Gupta et al., 1979).

Anatomical studies have identified raphé-projecting neurons within the preoptic area (Hermann et al., 1997; Nakamura et al., 
2009; Yoshida et al., 2009). A major group has been found in the ventral part of the MnPO, extending ventrolaterally. A second population is located more caudally and laterally, lateral to the medial preoptic nucleus and is termed "dorsolateral preoptic area" by Yoshida et al. (2009). These cell groups correspond to our functionally defined RMPO and CLPO regions, respectively (Tanaka et al., 2009). The distribution of raphé-projecting neurons identified in the present study is consistent with those anatomical studies. Interestingly, most warm-responsive neurons were found in the CLPO, whereas cold-responsive neurons were in the RMPO. The implications of this are discussed below.

\section{Excitatory and inhibitory preoptic-raphé connections contribute to tail vasoconstrictor outflow}

It is considered that heat conservation mechanisms are under tonic inhibitory control by warm-sensitive preoptic neurons (Zhang et al., 1995; Rathner et al., 2008; Tanaka et al., 2009). Our unexpected finding of cold-responsive raphé-projecting preoptic neurons suggested that an additional mechanism may come into play when the skin is cooled. Finding that most cold-responsive neurons were in the RMPO, we then showed that neuronal disinhibition or electrical stimulation of this region excited tail SNA, consistent with an excitatory descending connection from the RMPO driving tail SNA. This model is supported also by the close match between the antidromic conduction times of raphéprojecting neurons and the orthodromic conduction times measured from tail SNA responses to electrical stimulation of the RMPO and medullary raphé. Finally, the functional importance of this descending excitatory input is demonstrated by the finding that kynurenate injected into the medullary raphé abolished the tail SNA response to neuronal disinhibition of the RMPO.

Raphé kynurenate injections abolished the initial tail SNA response to our skin cooling protocol, the component driven purely by skin temperature (Owens et al., 2002). Interestingly, the delayed component of the response [attributable to the fall in core temperature (Owens et al., 2002)] was attenuated. Removal of glutamatergic excitatory inputs would be expected to reduce the excitability of raphé premotor neurons, and this may be why tail SNA responses to core cooling were attenuated. This explanation is consistent with the findings that tail SNA is maintained by synergistic drives, such that removal of one such drive lowers the sensitivity to another (Ootsuka and McAllen, 2005) and that an unidentified brainstem source provides tonic excitatory drive to tail SNA (Rathner et al., 2008).

Despite our previous demonstration (Tanaka et al., 2009) and confirmation here, that neurons in the RMPO provide a tonic inhibitory drive to tail SNA, few warm-responsive raphéprojecting neurons were found there. Although this could be attributable to limited sampling, it may be that the tonic inhibitory link from the RMPO to the medullary raphé is indirect [e.g., via the rostral periaqueducal gray (Zhang et al., 1997; Yoshida et al., 2005)]. Few cold-responsive neurons were identified in the CLPO, and neuronal disinhibition of that region failed to excite tail SNA. This suggests that, within the CLPO, warm-responsive raphé-projecting neurons predominate and that these regulate tail SNA by inhibitory control of the sympathetic premotor neurons of the medullary raphé. Interestingly, bicuculline injection into the CLPO not only failed to excite but also failed to inhibit tail SNA. This finding implies that the relevant CLPO neurons, although they possess inhibitory GABA receptors (Tanaka et al., 2009), receive no tonic $\mathrm{GABA}_{\mathrm{A}}$ receptor-mediated inhibition.

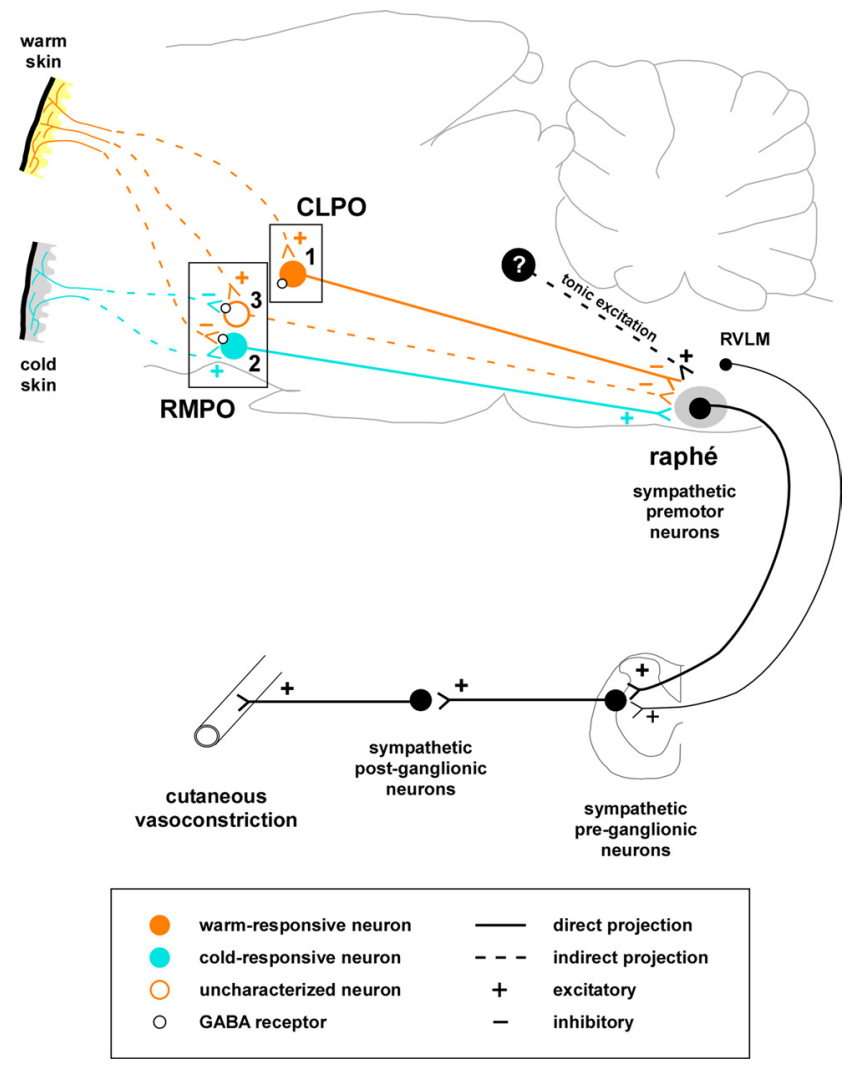

Figure 12. Diagram of neuronal pathways regulating tail vasoconstriction suggested by the present and previous findings. Starting from the right, sympathetic premotor neurons in the medullary raphé, and to a lesser extent the rostral ventrolateral medulla (RVLM), regulate tail vasomotor tone by exciting sympathetic preganglionic neurons. Those sympathetic premotor neurons receive tonic excitatory drive from unknown sources caudal to the preoptic area. Warm-responsive raphé-projecting neurons in the CLPO (1) show ongoing discharge in the warm, are inhibited by cooling, and contribute to tonic inhibition of tail sympathetic drive. Cold-responsive neurons, mostly in the RMPO (2), contribute to glutamatergic excitatory drive to raphé premotor neurons. That drive is responsible for a significant part of the tail vasoconstriction in cold conditions. Uncharacterized neurons in the RMPO (3) have inhibitory GABA receptors and contribute to tonic inhibition of tail SNA (Tanaka et al., 2009), but we do not yet know whether they are warm-responsive. If they are warm-responsive, they may not project directly to the medullary raphé.

\section{Preoptic efferent pathways for cold defense}

The present findings have demonstrated that cold-induced tail vasoconstriction is attributable in part to active excitatory drive, presumptively from the RMPO, and not just to the withdrawal of tonic inhibitory drive (Fig. 12). When linked with previous findings, this provides additional evidence that heat conservation and thermogenic pathways may be separately organized, even within the preoptic area. Non-shivering thermogenesis is also under tonic inhibitory control by neurons in the CLPO region (Osaka, 2004; Nakamura and Morrison, 2007). It has been proposed that, for the control of BAT thermogenesis, cold signals from the skin activate GABAergic neurons in the RMPO region, which then inhibit a tonically active GABAergic projection from the CLPO region to the thermogenic drive pathway (in the $\mathrm{DMH}$ ) (Nakamura and Morrison, 2008b). Two inhibitory stages thus link the excitatory input from cold skin to the excitatory output driving thermogenesis. In contrast, the present data suggest that a direct excitatory pathway from the RMPO to the medullary raphé makes the efferent link between cold skin and tail vasoconstriction (Fig. 12). Core (brain) temperature signals apparently regulate tail SNA at least in part by inhibitory connections to the 
medullary raphé (Tanaka et al., 2002), and the warm-responsive raphé-projecting neurons in the CLPO identified in the present study are candidates for this function. The observation that neuronal disinhibition in the CLPO had no inhibitory effect on tail SNA suggests that, unlike thermogenesis, no GABAergic projection from the RMPO to the CLPO is required for heat conservation (Fig. 12). The idea that RMPO and CLPO neurons act in parallel rather than in series is further supported by the finding that independent lesions of either region fail to raise body temperature, but combined lesions of both areas cause a sustained rise in body temperature (Yoshida et al., 2009).

\section{References}

Andrew D, Craig AD (2001) Spinothalamic lamina I neurones selectively responsive to cutaneous warming in cats. J Physiol 537:489-495.

Berner NJ, Heller HC (1998) Does the preoptic anterior hypothalamus receive thermoafferent information? Am J Physiol 274:R9-R18.

Boulant JA (2000) Role of the preoptic-anterior hypothalamus in thermoregulation and fever. Clin Infect Dis 31:S157-S161.

Brown DL, Guyenet PG (1985) Electrophysiological study of cardiovascular neurons in the rostral ventrolateral medulla in rats. Circ Res 56:359-369.

Chen XM, Hosono T, Yoda T, Fukuda Y, Kanosue K (1998) Efferent projection from the preoptic area for the control of non-shivering thermogenesis in rats. J Physiol 512:883-892.

Craig AD, Krout K, Andrew D (2001) Quantitative response characteristics of thermoreceptive and nociceptive lamina I spinothalamic neurons in the cat. J Neurophysiol 86:1459-1480.

Darian-Smith I, Johnson KO, Dykes R (1973) “Cold" fiber population innervating palmar and digital skin of the monkey: responses to cooling pulses. J Neurophysiol 36:325-346.

Defrin R, Ohry A, Blumen N, Urca G (2002) Sensory determinants of thermal pain. Brain 125:501-510.

Duclaux R, Kenshalo DR Sr (1980) Response characteristics of cutaneous warm receptors in the monkey. J Neurophysiol 43:1-15.

Grahn DA, Heller HC (1989) Activity of most rostral ventromedial medulla neurons reflect EEG/EMG pattern changes. Am J Physiol 257:R1496-R1505.

Grahn DA, Radeke CM, Heller HC (1989) Arousal state vs. temperature effects on neuronal activity in subcoeruleus area. Am J Physiol 256: R840-R849.

Gupta BN, Nier K, Hensel H (1979) Cold-sensitive afferents from the abdomen. Pflugers Arch 380:203-204.

Hammel HT, Hardy JD, Fusco MM (1960) Thermoregulatory responses to hypothalamic cooling in unanesthetized dogs. Am J Physiol 198:481-486.

Hellon RF, Misra NK (1973) Neurones in the dorsal horn of the rat responding to scrotal skin temperature changes. J Physiol 232:375-388.

Hellon RF, Hensel H, Schäfer K (1975) Thermal receptors in the scrotum of the rat. J Physiol 248:349-357.

Hermann DM, Luppi PH, Peyron C, Hinckel P, Jouvet M (1997) Afferent projections to the rat nuclei raphe magnus, raphe pallidus and reticularis gigantocellularis pars $\alpha$ demonstrated by iontophoretic application of choleratoxin (subunit b). J Chem Neuroanat 13:1-21.

Kanosue K, Nakayama T, Ishikawa Y, Hosono T, Kaminaga T, Shosaku A (1985) Responses of thalamic and hypothalamic neurons to scrotal warming in rats: non-specific responses? Brain Res 328:207-213.

Lipski J (1981) Antidromic activation of neurones as an analytic tool in the study of the central nervous system. J Neurosci Methods 4:1-32.

Madden CJ, Morrison SF (2004) Excitatory amino acid receptors in the dorsomedial hypothalamus mediate prostaglandin-evoked thermogenesis in brown adipose tissue. Am J Physiol Regul Integr Comp Physiol 286:R320-R325.

Magoun HW, Harrison F, Brobeck JR, Ranson SW (1938) Activation of heat loss mechanisms by local heating of the brain. J Neurophysiol 1:101-114.

Morrison SF, Nakamura K, Madden CJ (2008) Central control of thermogenesis in mammals. Exp Physiol 93:773-797.

Nagashima K, Nakai S, Tanaka M, Kanosue K (2000) Neuronal circuitries involved in thermoregulation. Auton Neurosci 85:18-25.

Nakamura K, Morrison SF (2007) Central efferent pathways mediating skin cooling-evoked sympathetic thermogenesis in brown adipose tissue. Am J Physiol Regul Integr Comp Physiol 292:R127-R136.
Nakamura K, Morrison SF (2008a) A thermosensory pathway that controls body temperature. Nat Neurosci 11:62-71.

Nakamura K, Morrison SF (2008b) Preoptic mechanism for cold-defensive responses to skin cooling. J Physiol 586:2611-2620.

Nakamura K, Morrison SF (2010) A thermosensory pathway mediating heat-defense responses. Proc Natl Acad Sci U S A 107:8848-8853.

Nakamura K, Matsumura K, Hübschle T, Nakamura Y, Hioki H, Fujiyama F, Boldogköi Z, König M, Thiel HJ, Gerstberger R, Kobayashi S, Kaneko T (2004) Identification of sympathetic premotor neurons in medullary raphe regions mediating fever and other thermoregulatory functions. J Neurosci 24:5370-5380.

Nakamura Y, Nakamura K, Morrison SF (2009) Different populations of prostaglandin EP3 receptor-expressing preoptic neurons project to two fever-mediating sympathoexcitatory brain regions. Neuroscience 161:614-620.

Nakayama T, Eisenman JS, Hardy JD (1961) Single unit activity of anterior hypothalamus during local heating. Science 134:560-561.

Ootsuka Y, Blessing WW (2005) Inhibition of medullary raphé/parapyramidal neurons prevents cutaneous vasoconstriction elicited by alerting stimuli and by cold exposure in conscious rabbits. Brain Res 1051:189-193.

Ootsuka Y, McAllen RM (2005) Interactive drives from two brain stem premotor nuclei are essential to support rat tail sympathetic activity. Am J Physiol Regul Integr Comp Physiol 289:R1107-R1115.

Ootsuka Y, Blessing WW, McAllen RM (2004) Inhibition of rostral medullary raphé neurons prevents cold-induced activity in sympathetic nerves to rat tail and rabbit ear arteries. Neurosci Lett 357:58-62.

Osaka T (2004) Cold-induced thermogenesis mediated by GABA in the preoptic area of anesthetized rats. Am J Physiol Regul Integr Comp Physiol 287:R306-R313.

Osborne PG, Kurosawa M (1994) Perfusion of the preoptic area with muscimol or prostaglandin $\mathrm{E}_{2}$ stimulates cardiovascular function in anesthetized rats. J Auton Nerv Syst 46:199-205.

Owens NC, Ootsuka Y, Kanosue K, McAllen RM (2002) Thermoregulatory control of sympathetic fibres supplying the rat's tail. J Physiol 543:849-858.

Paxinos G, Watson C (1998) The rat brain in stereotaxic coordinates, Ed 4. San Diego: Academic.

Rathner JA, Madden CJ, Morrison SF (2008) Central pathway for spontaneous and prostaglandin $\mathrm{E}_{2}$-evoked cutaneous vasoconstriction. Am J Physiol Regul Integr Comp Physiol 295:R343-R354.

Riedel W (1976) Warm receptors in the dorsal abdominal wall of the rabbit. Pflugers Arch 361:205-206.

Riffenburgh RH, Cummins KM (2006) A simple and general change-point identifier. Stat Med 25:1067-1077.

Smith JE, Jansen AS, Gilbey MP, Loewy AD (1998) CNS cell groups projecting to sympathetic outflow of tail artery: neural circuits involved in heat loss in the rat. Brain Res 786:153-164.

Spray DC (1986) Cutaneous temperature receptors. Annu Rev Physiol 48:625-638.

Tanaka M, McAllen RM (2005) A subsidiary fever center in the medullary raphé? Am J Physiol Regul Integr Comp Physiol 289:R1592-R1598.

Tanaka M, Nagashima K, McAllen RM, Kanosue K (2002) Role of the medullary raphé in thermoregulatory vasomotor control in rats. J Physiol 540:657-664.

Tanaka M, Ootsuka Y, McKinley MJ, McAllen RM (2007) Independent vasomotor control of rat tail and proximal hairy skin. J Physiol 582: 421-433.

Tanaka M, McKinley MJ, McAllen RM (2009) Roles of two preoptic cell groups in tonic and febrile control of rat tail sympathetic fibers. Am J Physiol Regul Integr Comp Physiol 296:R1248-R1257.

Yoshida K, Konishi M, Nagashima K, Saper CB, Kanosue K (2005) Fos activation in hypothalamic neurons during cold or warm exposure: projections to periaqueductal gray matter. Neuroscience 133:1039-1046.

Yoshida K, Li X, Cano G, Lazarus M, Saper CB (2009) Parallel preoptic pathways for thermoregulation. J Neurosci 29:11954-11964.

Zhang YH, Yanase-Fujiwara M, Hosono T, Kanosue K (1995) Warm and cold signals from the preoptic area: which contribute more to the control of shivering in rats? J Physiol 485:195-202.

Zhang YH, Hosono T, Yanase-Fujiwara M, Chen XM, Kanosue K (1997) Effect of midbrain stimulations on thermoregulatory vasomotor responses in rats. J Physiol 503:177-186. 